\title{
Comparison of Modern 3D and 2D MR Imaging Sequences of the Wrist at 3 Tesla
}

\section{Vergleich moderner 3D- und 2D-MR-Sequenzen zur Bildgebung der Hand bei 3 Tesla}

Authors

Affiliations
C. Rehnitz' , B. Klaan' ${ }^{1}$, F. von Stillfried², E. Amarteifio' ${ }^{1}$, I. Burkholder ${ }^{3}$, H. U. Kauczor ${ }^{1}$, M. A. Weber ${ }^{1}$

Diagnostic and Interventional Radiology, University of Heidelberg, Germany

Department for Orthopedics, Traumatology and Paraplegiology, University of Heidelberg, Germany

3 Department of Nursing and Health, University of Applied Sciences of the Saarland, Saarbruecken, Germany

Key words
wrist
hand
3 Tesla
3D imaging
cartilage imaging
MR imaging

received $\quad 21.12 .2015$ accepted 1.3.2016

Bibliography Dol http://dx.doi.org/ 10.1055/s-0042-104512 Published online: 3.5.2016 Fortschr Röntgenstr 2016; 188: 753-762 @ Georg Thieme Verlag KG Stuttgart . New York . ISSN 1438-9029

\section{Correspondence \\ Dr. Christoph Rehnitz}

Klinik für Diagnostische und Interventionelle Radiologie, Universitätsklinik Heidelberg INF 110

69121 Heidelberg

Germany

Tel.: ++49/6221/966429

Fax: ++ 49/62 21/966640 Christoph.rehnitz@med.uniheidelberg.de

\section{Zusammenfassung}

$\nabla$

Ziel: Vergleich der Bildqualität moderner 3D- und 2D-Sequenzen zur dedizierten MRT des Handgelenkes bei 3 Tesla $(T)$.

Material und Methoden: Bei 18 Patienten mit Handgelenksschmerzen (mittleres Alter: 36,2 Jahre) und 16 gesunden Probanden (mittleres Alter: 26,4 Jahre) wurde eine 3T MRT-Bildgebung des Handgelenkes unter Einschluss einer 2D-Protonen-gewichteten fettgesättigten (PDfs) Sequenz und drei isotropen 3D-Sequenzen (TrueFISP, MEDIC und PDfs SPACE) durchgeführt. Die subjektive Bildqualität wurde auf einer 5-Punkte-Skala (04) bewertet und umfasste die Gesamtbildqualität (OIQ), die Beurteilbarkeit von Knorpel/Ligamenten/TFCC sowie das Ausmaß von Artefakten. Das Signal-zu-Rausch- (SNR) und Kontrast-zu-RauschVerhältnis (CNR) von Knorpel/Knochen/Muskel/ Flüssigkeit sowie das gemittelte Gesamt-SNR/CNR wurden mittels Region-of-Interest-Analyse berechnet. Die statistische Auswertung erfolgte unter Verwendung von Varianzanalysen sowie gepaarten t- und Wilcoxon-Rangsummen-Tests.

Ergebnisse: Die Bildqualität aller getesteten Sequenzen war der 3D-PDfs-SPACE überlegen $(p<0,01)$. Bezüglich des Knorpels erreichte die 3DTrueFISP die höchste kombinierte Bewertung (Mittelwert: 3,4), wobei die Unterschiede zur 2D-PDfs in beiden Gruppen und der 3D-PDfs-SPACE in der Probanden-Gruppe signifikant waren $(p<0,05)$. Die 3D-MEDIC war in 7 von 8 Paarvergleichen bezüglich der Ligamente und des TFCC $(p<0,05)$ überlegen. Die 2D-PDfs lieferte konstant hohe Bewertungen. Die gemittelten SNR/CNR-Werte für 2D-PDfs, 3D-PDfs-SPACE, 3D-TrueFISP, und 3DMEDIC waren 68/65, 32/27, 45/47 und 57/45. Bezüglich der anatomischen Einzelstrukturen war die 2D-PDfs in den meisten Einzelvergleichen überlegen $(p<0,05)$, unter den 3D-Sequenzen die 3D$\operatorname{MEDIC}(\mathrm{p}<0,05)$.

\section{Abstract \\ $\nabla$}

Purpose: To compare the image quality of modern $3 \mathrm{D}$ and $2 \mathrm{D}$ sequences for dedicated wrist imaging at 3 Tesla (T) MRI.

Materials and Methods: At 3T MRI, 18 patients (mean age: 36.2 years) with wrist pain and 16 healthy volunteers (mean age: 26.4 years) were examined using $2 \mathrm{D}$ proton density-weighted fat-saturated (PDfs), isotropic 3 D TrueFISP, 3 D MEDIC, and $3 \mathrm{D}$ PDfs SPACE sequences. Image quality was rated on a five-point scale $(0-4)$ including overall image quality (OIQ), visibility of important structures (cartilage, ligaments, TFCC) and degree of artifacts. Signal-to-noise ratios (SNR) and contrast-to-noise ratios (CNR) of cartilage/bone/muscle/fluid as well as the mean overall SNR/CNR were calculated using region-of-interest analysis. ANOVA, paired $\mathrm{t}$-, and Wilcoxon-signed-rank tests were applied. Results: The image quality of all tested sequences was superior to 3 D PDfs SPACE ( $p<0.01$ ). 3 D TrueFISP had the highest combined cartilage score (mean: 3.4) and performed better in cartilage comparisons against $3 \mathrm{D}$ PDfs SPACE in both groups and 2 D PDfs in volunteers $(\mathrm{p}<0.05)$. $3 \mathrm{D}$ MEDIC performed better in 7 of 8 comparisons $(p<0.05)$ regarding ligaments and TFCC. 2D PDfs provided constantly high scores. The mean overall SNR/CNR for $2 \mathrm{D}$ PDfs, $3 \mathrm{D}$ PDfs SPACE, $3 \mathrm{D}$ TrueFISP, and $3 \mathrm{D}$ MEDIC were 68/65, 32/27, 45/47, and 57/45, respectively. 2D PDfs performed best in most SNR/CNR comparisons $(p<0.05)$ and 3 D MEDIC performed best within the $3 \mathrm{D}$ sequences $(\mathrm{p}<0.05)$. Conclusion: Except $3 \mathrm{D}$ PDfs SPACE, all tested $3 \mathrm{D}$ and $2 \mathrm{D}$ sequences provided high image quality. 3D TrueFISP was best for cartilage imaging, 3 D MEDIC for ligaments and TFCC and 2D PDfs for general wrist imaging.

Key points:

$\checkmark 3 \mathrm{D}$ TrueFISP is recommended for cartilage imaging of the wrist at $3 \mathrm{~T}$. 
Schlussfolgerung: Mit Ausnahme der 3D-PDfs-SPACE zeigten alle untersuchten 3D- und 2D-Sequenzen eine sehr gute Bildqualität. Die 3D-TrueFISP war die beste 3D-Sequenz zur Knorpelbildgebung, die 3D-MEDIC zur Darstellung der Ligamente und des TFCC und die 2D-PDfs zur allgemeinen Bildgebung aller Strukturen.

Kernaussagen:

Die 3D-TrueFISP wird zur Knorpelbildgebung der Hand bei $3 \mathrm{~T}$ empfohlen.

Die 3D-MEDIC empfiehlt sich zur Beurteilung der Ligamente und des TFCC.

> Die robuste 2D-PDfs sollte Bestandteil von Routine-Protokollen sein und je nach klinischer Fragstellung durch 3D-Sequenzen ergänzt werden.

$\checkmark$ Die 3D-PDfs-SPACE ist den übrigen getesteten Sequenzen unterlegen.

\section{Introduction}

\section{$\nabla$}

MR imaging of the wrist is challenging, because of its complex anatomy and small structures including tiny ligaments with oblique courses as well as thin cartilage layers. However, ligament tears, damage to the cartilage, injuries of the triangular fibro-cartilage complex (TFCC) or lesions of tendons are frequent clinical questions in patients with general wrist pain, beginning osteoarthritis or after trauma [1]. The $2 \mathrm{D}$ proton density fat-saturated (PDfs) turbo spin echo (TSE) sequence is a standard sequence in general musculoskeletal imaging and has also been advocated for the wrist $[1,2]$. Modern $3 \mathrm{D}$ sequences that have been used in other joints to evaluate cartilage, ligaments, and tendons include 3 D TSE-based PDfs SPACE (sampling perfection with application-optimized contrast using different flip-angle evolutions), $3 \mathrm{D}$ gradient-echo (GRE) based sequences MEDIC (multiple echo data image combination) and TrueFISP (True Fast Imaging with Steady-state Precession). However, these sequences have not been systematically applied at the wrist. Also, there are conflicting results regarding the performance of $3 \mathrm{D}$ versus $2 \mathrm{D}$ MR imaging in other joints [3-6] and at the wrist at $3 \mathrm{~T}[2,7,8]$. Moreover, many studies on the assessment of the diagnostic performance of these sequences only studied healthy volunteers [9, 10 ] including all reports on $3 \mathrm{D} / 2 \mathrm{D}$ imaging of the wrist at $3 \mathrm{~T}$ [2, 7,8 ]. The purpose of this study was to evaluate the image quality measures of three modern high-resolution $3 \mathrm{D}$ sequences and high-resolution $2 \mathrm{D}$ PDfs sequences at the wrist in patients with wrist pain and healthy volunteers at $3 \mathrm{~T}$.

\section{Materials and Methods}

$\nabla$

\section{Subjects}

The study was approved by the institutional review board and conducted according to the declaration of Helsinki in the present form. Informed consent was obtained from all patients and volunteers after the nature of the examination had been fully explained.

A group of 34 individuals with $3 \mathrm{~T}$ wrist imaging was included in this study from March 2012 through October 2012. It consisted of 18 consecutive patients ( 10 women and 8 men; mean age: 36.2 years; age range: 22 - 55 years) that presented at the hand surgery department of the orthopedic clinic of our institution for the evaluation of acute or chronic wrist pain and 16 healthy volunteers ( 10 women and 6 men; mean age: 26.4 years; age range:
3 $\mathrm{D}$ MEDIC is recommended for ligaments and TFCC.

$\checkmark$ Robust $2 \mathrm{D}$ PDfs should be used in routine protocols. $3 \mathrm{D}$ sequences may be added depending on the clinical question.

$\checkmark 3$ D PDfs SPACE is currently inferior.

Citation Format:

- Rehnitz C, Klaan B, von Stillfried F et al. Comparison of Modern 3D and 2D MR Imaging Sequences of the Wrist at 3 Tesla. Fortschr Röntgenstr 2016; 188: 753-762

22 - 31 years). The volunteers showed a normal physical examination of the wrist performed by an orthopedic hand surgeon and no history of wrist trauma, wrist surgery, or any clinical complaints regarding their wrists. Wrist pain was assessed by physical examination by a senior hand surgeon and included patients with posttraumatic pain $(\mathrm{n}=11)$, ulnar impaction syndrome $(n=2)$, and pain without clearly defined clinical pathology $(n=5) .5$ of the patients had previous surgery at the wrist. Patients who were referred for tumor imaging with the need of specialized imaging protocols as well as patients with acute septic conditions were not included. Further exclusion criteria were general contraindications to MR imaging (for example, pacemakers, none of the individuals), patients who could not be imaged with the dedicated wrist coil for several reasons (for example, not fitting in the coil, $n=4$ ), or presence of metallic implants at the wrist $(n=1)$. Therefore, of the original 23 patients, only 18 with wrist pain were included. In the group of volunteers the left wrist was examined, while in the group of patients the clinically affected wrist was imaged (6 right and 12 left wrists).

\section{MR Imaging Protocol}

MRI was performed on a 70-cm open-bore $3 \mathrm{~T}$ whole-body scanner (MAGNETOM Verio, Siemens Healthcare, Erlangen, Germany), equipped with an 18-channel total imaging matrix (Tim [102x18] configuration) in combination with a dedicated transmit-receive eight-channel wrist coil (Siemens Healthcare, Erlangen, Germany). The examination protocol was adapted according to previous recommendations [1]. The subjects were placed in a prone position with the elbow extended overhead and the wrist coil placed in the isocenter. The same imaging protocol was used for all volunteers and patients and included the standard high-resolution two-dimensional PD-weighted fat-saturated TSE sequence (2 D PDfs) and the three isotropic three-dimensional sequences: $3 \mathrm{D}$ PDfs SPACE, 3 D MEDIC, and 3 D TrueFISP. The technical parameters for all sequences are summarized in $\bullet$ Table 1. During initial testing, the $3 \mathrm{D}$ TrueFISP exceeded SAR limits with the imaging parameters provided by the manufacturer, necessitating slight modifications of the flip angle, echo time (TE) and repetition time (TR). The other sequences were used as originally provided by the manufacturer. All sequences were acquired in coronal orientation without secondary reconstruction.

\section{Data Acquisition}

The image analysis was performed on our picture archiving and communication system (Centricity PACS, version 4.0, GE Health- 


\begin{tabular}{|lllll|} 
& 2D PD fs & 3D PD fsSPACE & 3 D MEDIC & 3 D TrueFISP \\
\hline TR $(\mathrm{ms})$ & 2820 & 1100 & 40 & 9.53 \\
\hline TE $(\mathrm{ms})$ & 26 & 26 & 22 & 4.77 \\
\hline flip angle (degree) & 156 & 120 & 10 & 18 \\
\hline matrix & $307 * 384$ & $240 * 320$ & $320 * 240$ & $288 * 384$ \\
\hline voxel size $(\mathrm{mm})$ & $0.37 \times 0.37 \times 2$ & $0.4 \times 0.4 \times 0.4$ & $0.4 \times 0.4 \times 0.4$ & $0.5 \times 0.5 \times 0.5$ \\
\hline field of view $(\mathrm{mm})$ & $105 \times 140$ & $105 \times 140$ & $105 \times 140$ & $105 \times 140$ \\
\hline slice thickness $(\mathrm{mm})$ & 2 & 0.4 & 0.4 & 0.5 \\
\hline spacing $(\mathrm{mm})$ & 2.2 & - & - & - \\
\hline bandwidth $(\mathrm{Hz} /$ pixel) & 171 & 326 & 158 & 318 \\
\hline echo train lengths & 7 & 36 & 1 & 1 \\
\hline iPAT & GRAPPA & GRAPPA & GRAPPA & GRAPPA \\
\hline PAT factor & 2 & 2 & 2 & 2 \\
\hline acquisition time $(\mathrm{min})$ & $2: 40$ & $6: 11$ & $3: 36$ & $4: 32$ \\
\hline
\end{tabular}

Table 1 MR imaging protocol.

Tab. 1 MRT-Protokoll.

$T R=$ repetition time; TE = echo time; $P$ PAT = integrated parallel acquisition techniques; GRAPPA: generalized autocalibrating partially parallel acquisition; PD fs: proton density-weighted fat saturated; SPACE: sampling perfection with application-optimized contrast using different flip angle evolutions; MEDIC: multiple echo data image combination; TrueFISP: true fast imaging with steady-state precession.

care Integrated IT Solutions, Barrington, IL). The evaluation was performed in consensus by 2 musculoskeletal radiologists with 10 and 1 year of experience in this field, respectively.

Subjective image quality assessment: qualitative analysis The image quality of all sequences was assessed and subjectively rated using a five-point scale and included 5 different items:

1. Cartilage

2. Triangular fibro-cartilage complex (TFCC)

3. Intercarpal ligaments

4. Artifacts

5. Overall image quality (OIQ)

In general, a score of 0 meant that the structure/sequence was not evaluable; 1 : indicated poor image quality; 2 : moderate image quality; 3 : high image quality, and 4: excellent or outstanding image quality.

The grading for the anatomical structures was defined as the calculated average of different separately graded substructures: for cartilage, it represented the average of radio-scaphoidal and intercarpal cartilage, and for TFCC the average of the gradings for the central disc, ulnar attachments, and meniscal homologue. For intercarpal ligaments, the average grading of the scapholunate und lunotriquetral ligaments was calculated. For the anatomical structures, a score of 0 indicated that a structure was not visible; a score of 1 indicated that a structure was visible, but could not be analyzed; a score of 2 indicated that a structure was visible and partially assessable, i.e., not all aspects of the structure could be analyzed (for example, small lesion or partial tears might not be visible); a score of 3 indicated that a structure was visible and completely analyzable; with this score, the corresponding sequence should enable detection of all major pathologies; a score of 4 indicated that a structure was excellently visible, sharply outlined, and with a homogeneous signal. The sequence with outstanding image quality score may allow for detection of subtle pathologic changes within the structure.

The scoring of artifacts was based on the severity of artifacts (for instance, banding, chemical shift, movement or susceptibility artifacts) in combination with the resulting impairment of the diagnostic interpretability of the key structures including cartilage, the central disc of the TFCC, and intercarpal ligaments. A score of 0 meant the sequence was not evaluable due to artifacts; a score of 1 indicated severe diagnostic impairment; a score of 2 indicated moderate diagnostic impairment; a score of 3 indicated mild diagnostic impairment, and a score of 4 indicated no diagnostic impairment.

The overall image quality (OIQ) was graded based on the personal overall impression of the sequence regarding important features of image quality including signal intensity, visible noise, uniformity, sharpness, and contrast between different structures/tissues. Therefore, a grade four (excellent) was only given if the sequence could sharply visualize all tissues and relevant anatomic structures (for example, cartilage or TFCC) in a manner that would potentially allow for the detection of subtle pathologic changes.

\section{Quantitative Analysis: SNR and CNR}

Additionally, the SNR (signal-to-noise ratio) and CNR (contrastto-noise ratio) of all sequences were determined by signal intensity measurements in consistent locations for each subject. Both observers were blinded concerning the identity of the subject and the sequence. To gain the specific SNR and CNR of different tissues, manually defined ROIs were placed within the following anatomical structures: intercarpal cartilage, bone, muscle, fluid, TFCC, and tendon. The signal intensity of cartilage $\left(\mathrm{SI}_{\text {cartilage }}\right)$ was measured in the distal carpal row between the capitate and scaphoid as well as the lunate bone, $\mathrm{SI}_{\text {bone }}$ within bone marrow of the capitate or hamate, $\mathrm{SI}_{\text {muscle }}$ within the thenar muscles, $\mathrm{SI}_{\text {fluid }}$ within the radio-scaphoidal joint cavity or between the proximal and distal carpal row, $\mathrm{SI}_{\mathrm{TFCC}}$ within the central disc of the TFCC, and $\mathrm{SI}_{\text {tendon }}$ within the extensor tendons close to the carpal tunnel. Noise was defined and measured as the standard deviation of signal intensity within the air in an artifact-free area outside of the extremity [10]. The mean sizes of the ROIs for the different anatomical structures was $51.0 \mathrm{~mm}^{2}$ for noise (range: $49-53$ ), $14.1 \mathrm{~mm}^{2}$ for cartilage (range: $\left.6-24\right), 30.9 \mathrm{~mm}^{2}$ for bone (range: $30-34$ ), $30.8 \mathrm{~mm}^{2}$ for muscle (range: $29-33$ ), $2.6 \mathrm{~mm}^{2}$ for fluid (range: $1-7$ ), $7.8 \mathrm{~mm}^{2}$ for TFCC (range: $2-15$ ), and $21.8 \mathrm{~mm}^{2}$ for tendon (range: $19-24$ ).

SNR was calculated according to [10] as

$\mathrm{SNR}_{\text {tissue }}=\frac{\mathrm{SI}_{\text {tissue }}}{1.5 \cdot \text { noise }}$

CNR between two tissues was defined according to [10] as $\mathrm{CNR}_{\text {tissue1-tissue 2 }}=\frac{\mathrm{SI}_{\text {tissue 1 }}-\mathrm{SI}_{\text {tissue 2 }}}{1.5 \cdot \text { noise }}$ 
CNR was calculated for various comparisons of assessed tissues, specifically for cartilage-bone, muscle-bone, fluid-cartilage, and muscle-tendon. Differences between each sequence regarding SNR/CNR in a specific tissue were assessed using a two-pair comparison of the sequences for all tissues, for instance $2 \mathrm{D}$ PDfs versus $3 \mathrm{D}$ PDfs SPACE regarding the SNR of cartilage. The SNR and the CNR comparisons were both performed divided for the groups of volunteers and patients. To increase overall comparability between the sequences, additionally, the mean overall SNR and CNR in the entire study population (volunteers and patients) were calculated as mean values and standard deviation of all tissues together (see also the statistics section).

\section{Statistical Analysis}

All statistical analyses were processed using SAS for Windows version 9.3 (SAS Institute Inc., Cary, NC) and R version 2.15.1 (www.cran.r-project.org). Quantitative and qualitative measurements were analyzed separately for the groups of volunteers and patients. Additionally, a combined analysis was performed for the qualitative items. The homogeneity of the groups regarding sex and age were tested using the Chi-square test and exact Wilcoxon rank-sum test, respectively. Image quality grading was assessed using the Friedman test for paired samples to analyze whether significant differences between the four sequences existed in a certain structure or category. Friedman's test is a nonparametrical alternative to ANOVA with repeated measures and is used to test for differences between more than two groups. Only if significant differences were found, post-hoc two-group comparisons between all sequences were performed using the Wilcoxon signed-rank test. The Bonferroni-Holm method was used to adjust p-values of the Wilcoxon-signed-rank test regarding multiple comparisons. Differences in SNR and CNR between various sequences were assessed using a one-way ANOVA analysis with repeated measurements. F-tests were used to analyze overall differences between all sequences. Only if significant overall differences were found in this global test, post-hoc analysis using paired t-tests was performed comparing all sequences with each other in groups of two applying the Bonferroni-Holm method to adjust p-values of paired t-tests regarding multiple comparisons. The mean overall SNR and CNR of the whole study population (volunteers and patients) was calculated as mean values and standard deviation of all tissues, i.e., mean overall SNR/ CNR of 2 D PDfs, 3 D PDfs SPACE, 3 D MEDIC, and 3D TrueFISP. A p-value of less than 0.05 was considered significant.

\section{Results}

\section{Subjective image quality analyses}

2 D PDfs, 3 D TrueFISP, and 3 D MEDIC showed high to excellent overall image quality levels (mostly equaling grade $3-4$ ), while 3 D PDfs SPACE provided the lowest ( $\bullet$ Fig. 1). The best image quality was found for 3 D TrueFISP in volunteers (mean: 3.6), mainly due to its high resolution, clarity, and delineation of structures, high signal of cartilage and fluid and homogeneous dark signal of bone marrow ( $\bullet$ Fig. 2 ). Image quality measures were lower in patients when compared to healthy volunteers and most pronounced in 3 D TrueFISP ( $\bullet$ Fig. 1). The decrease in image quality was mainly attributed to motion in the longer $3 \mathrm{D}$ sequences, banding, and susceptibility artifacts. However, the banding and susceptibility artifacts usually limited the interpretability only regionally with good or excellent visibility in other regions. 0 Fig. 3 highlights the ima-

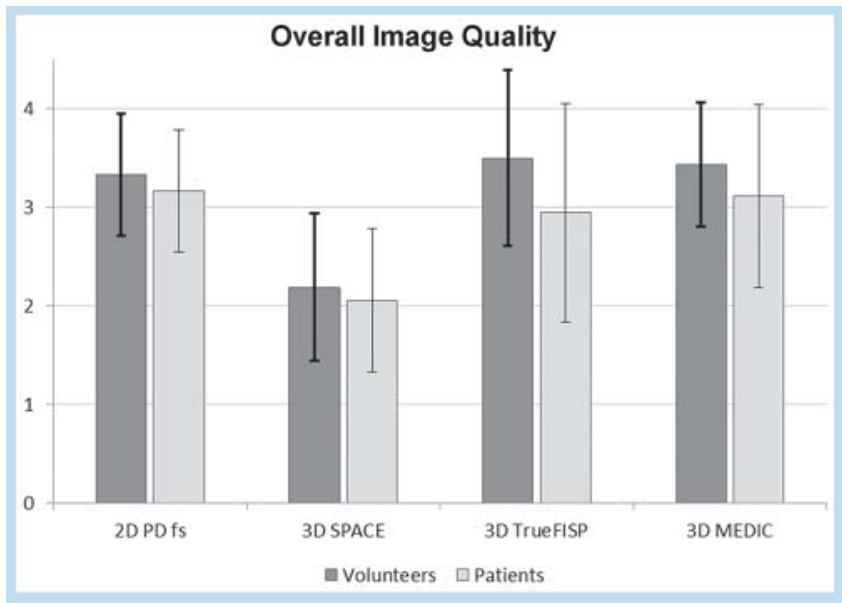

Fig. 1 Overall image quality for the four sequences separated for healthy volunteers and patients. Higher scores indicate higher quality. Note high quality of all sequences except 3 D PDfs SPACE (moderate) and the decrease in image quality in the patients compared to the volunteers.

Abb.1 Gesamt-Bildqualität der vier Sequenzen getrennt nach gesunden Probanden und Patienten. Höhere Werte entsprechen höherer Bildqualität. Beachte die hohe Bildqualität aller Sequenzen außer der 3D-PDfs-SPACE (moderat) und den Abfall der Bildqualität in der Patientengruppe verglichen mit den Probanden.

ging performance in a patient with lunate cartilage damage due to ulna impaction with a small cartilage defect best depicted in TrueFISP. Also, regionally decreased interpretability due to artifacts at the radioscaphoid joint is illustrated, which was pronounced in the GRE sequences TrueFISP and MEDIC compared to the TSEbased other sequences. However, noisy image impression was present in 3 D PDfs SPACE. For analyses of specific tissues, artifacts, and overall image quality of the different sequences, 60 two-pair comparisons between the sequences in volunteers and patients were performed ( $\bullet$ Table 2 ). $\bullet$ Fig. 4 compares combined (all individuals) image quality scores in these disciplines. 2D PDfs won most of the two-pair comparisons $(\mathrm{p}<0.01-\mathrm{p}<0.05)$. In particular, 2 D PDfs was superior in all comparisons ( $p<0.05$ ) against both $3 \mathrm{D}$ PDfs SPACE and 3D TrueFISP regarding ligaments and TFCC. Besides good results in all comparisons, $3 \mathrm{D}$ MEDIC was especially beneficial in ligaments and TFCC when compared to the other $3 \mathrm{D}$ sequences, winning 7 out of 8 comparisons $(\mathrm{p}<0.05)$ with one non-significant result. There was no significant difference between MEDIC and $2 \mathrm{D}$ PDfs in all image quality scores. However, the readers found an additional or complementary advantage of MEDIC, because of the isotropic resolution with thin continuous slices that facilitated analysis of the whole course of ligaments or TFCC attachments. MEDIC showed minor focal low intensity artifacts when depicting cartilage ( $\bullet$ Fig. 3 ). Besides the highest image quality score in volunteers, $3 \mathrm{D}$ TrueFISP also had the highest combined cartilage score (mean: $3.4 \pm 0.7$ ) and won the two-pair cartilage comparisons against 3 D PDfs SPACE $(p<0.05)$ in both groups and $2 \mathrm{D}$ PDfs in volunteers $(\mathrm{p}<0.05)$. The main advantages of $3 \mathrm{D}$ TrueFISP were the bright cartilage signal with excellent contrast to surrounding structures, especially to the joint fluid and the subchondral bone, enabling the readers to better depict subtle cartilage lesions ( $\bullet$ Fig. 3 ). The only two-pair comparison that 3 D PDfs SPACE won was the degree of artifacts in patients when compared to $3 \mathrm{D}$ TrueFISP, which also lead to a minor decrease of image quality in patients when compared to volunteers. Specifically, no band- 

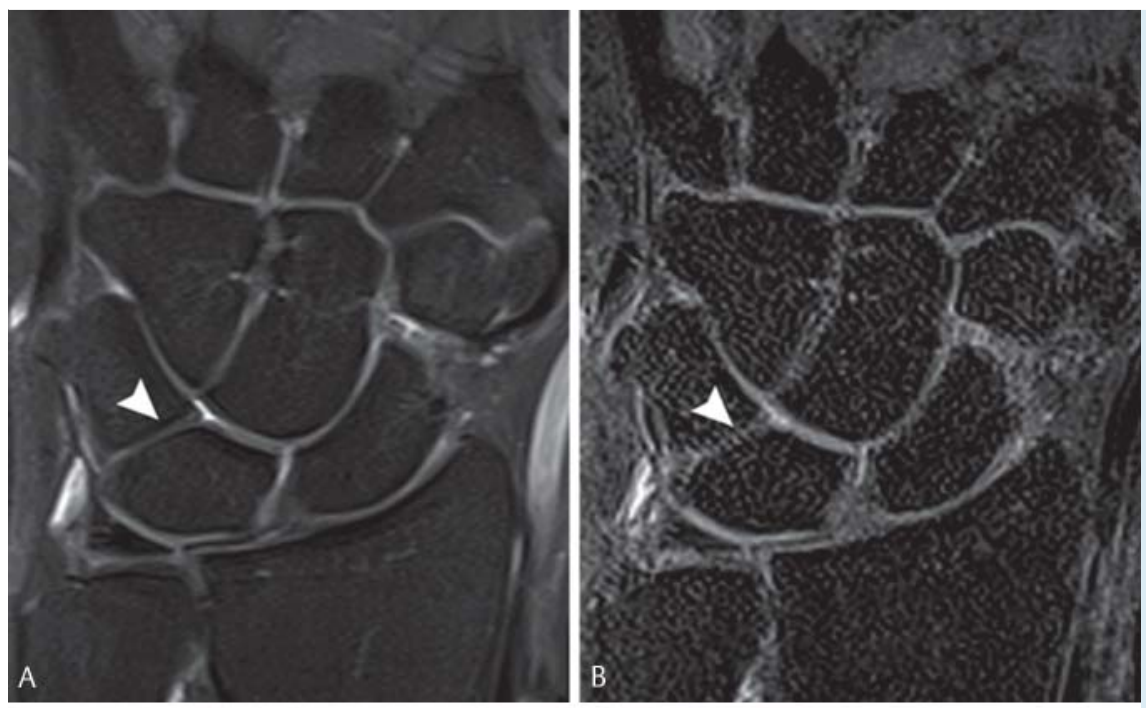

Fig. 2 A-D. Image quality comparison in a representative healthy 22-year-old female volunteer. Note differences in image quality for instance at the lunotriquetral joint (arrowheads). 3 D TrueFISP C provides high cartilage image quality with delineation of the two opposing cartilage layers and an excellent contrast to the bright joint fluid and the dark subchondral bone. 2D PD fs A and 3D MEDIC D provide good quality of all structures. Image blurring (arrow in B), "noisy" image impression and inferior structure delineation reduce overall image quality of 3D PDfs SPACE.

Abb.2 A-D. Vergleich der Bildqualität bei einer repräsentativen 22-jährigen gesunden Probandin. Beachte die Unterschiede in der Bildqualität, z. B. im lunotriquetralen Gelenk (Pfeilspitzen). Die 3DTrueFISP C bildet den Knorpel der beiden gegenüberliegenden Knorpelschichten in sehr hoher Qualität ab und zeigt einen exzellenten Kontrast
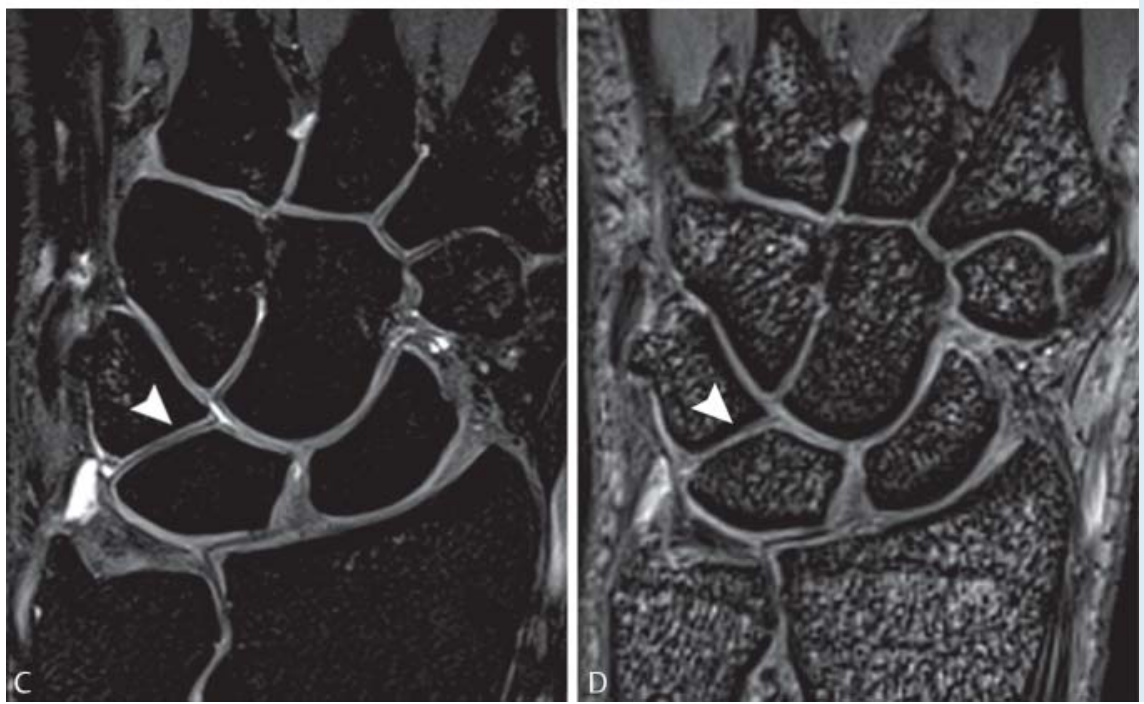
sowohl zu der hellen Gelenkflüssigkeit als auch zum dunklen subchondralen Knochen. Die 2D-PDfs A und die 3D-MEDIC D zeigen eine hohe Bildqualität für alle Strukturen. Unschärfe sowie sichtbares Rauschen (Pfeilspitze in B) und die schlechtere Abgrenzbarkeit der Strukturen führen zu einer geringeren Bildqualität der 3D-PDfs-SPACE.

ing or chemical shift artifacts were present. However, image quality measures were lowest. The main subjective disadvantages of 3 D PDfs SPACE were the visible noise and the blurring of the structures ( $\bullet$ Fig. 2,3 ) as well as motion artifacts in this sequence with the longest acquisition time of 6:11 min.

\section{Quantitative analyses}

- Fig. 5 shows the overall SNR and CNR for each sequence. 2D PDfs showed the highest SNR and CNR values. Within the $3 \mathrm{D}$ sequences, $3 \mathrm{D}$ MEDIC had the highest SNR and similar overall CNR values compared to $3 \mathrm{D}$ TrueFISP, while $3 \mathrm{D}$ PDfs SPACE showed the lowest SNR/CNR. For detailed analyses of the specific tissues, 120 two-pair comparisons between the sequences have been performed regarding SNR and CNR. $\odot$ Table 2 provides the winners of these benchmark challenges and the corresponding p-values of those comparisons. 2D PDfs won most of the two-pair comparisons ( $p<0.01-p<0.05)$. 3 D MEDIC turned out to be the best $3 \mathrm{D}$ sequence and won the majority of comparisons in the different tissues including ligaments, tendons, bone, and TFCC $(\mathrm{p}<0.01-\mathrm{p}<0.05)$. One exception was the CNR of cartilage/fluid and the SNR of fluid, where $3 \mathrm{D}$ TrueFISP was the best $3 \mathrm{D}$ sequence ( $\bullet$ Fig. 6 ).

\section{Discussion}

$\nabla$

In our study on wrist imaging at $3 \mathrm{~T}$, the tested $2 \mathrm{D} / 3 \mathrm{D}$ sequences turned out to be advantageous in different situations and specific tissues. For instance, $3 \mathrm{D}$ TrueFISP may be recommended for cartilage imaging, because it provided the highest cartilage image quality of all sequences, reaching significant levels versus $3 \mathrm{D}$ PDfs SPACE (all individuals) and 2D PDfs (volunteers). In most volunteers, the image quality of cartilage was by far better than all other sequences with excellent contrast to the very bright fluid and the dark subchondral bone. In several patients with cartilage defects, this damage was best visualized in $3 \mathrm{D}$ TrueFISP and contributed to the high cartilage score. An additional benefit of $3 \mathrm{D}$ TrueFISP was the highest CNR of cartilage/fluid and SNR of fluid of all $3 \mathrm{D}$ sequences. This in combination with its high resolution and isotropic voxels may facilitate the detection of cartilage defects, especially when regional cartilage integrity is crucial to decide between limited surgical procedures and total wrist arthrodesis $[12,13]$. TrueFISP has also proved advantages in cartilage imaging in other joints $[14,15]$. In a study of the knee joint [14], TrueFISP provided excellent image quality, reaching 3.78 \pm 0.5 from a maximum of 4 points in 37 patients after matrixassociated autologous chondrocyte transplantation (MACT). Also, TrueFISP was recommended for monitoring osteoarthritis 

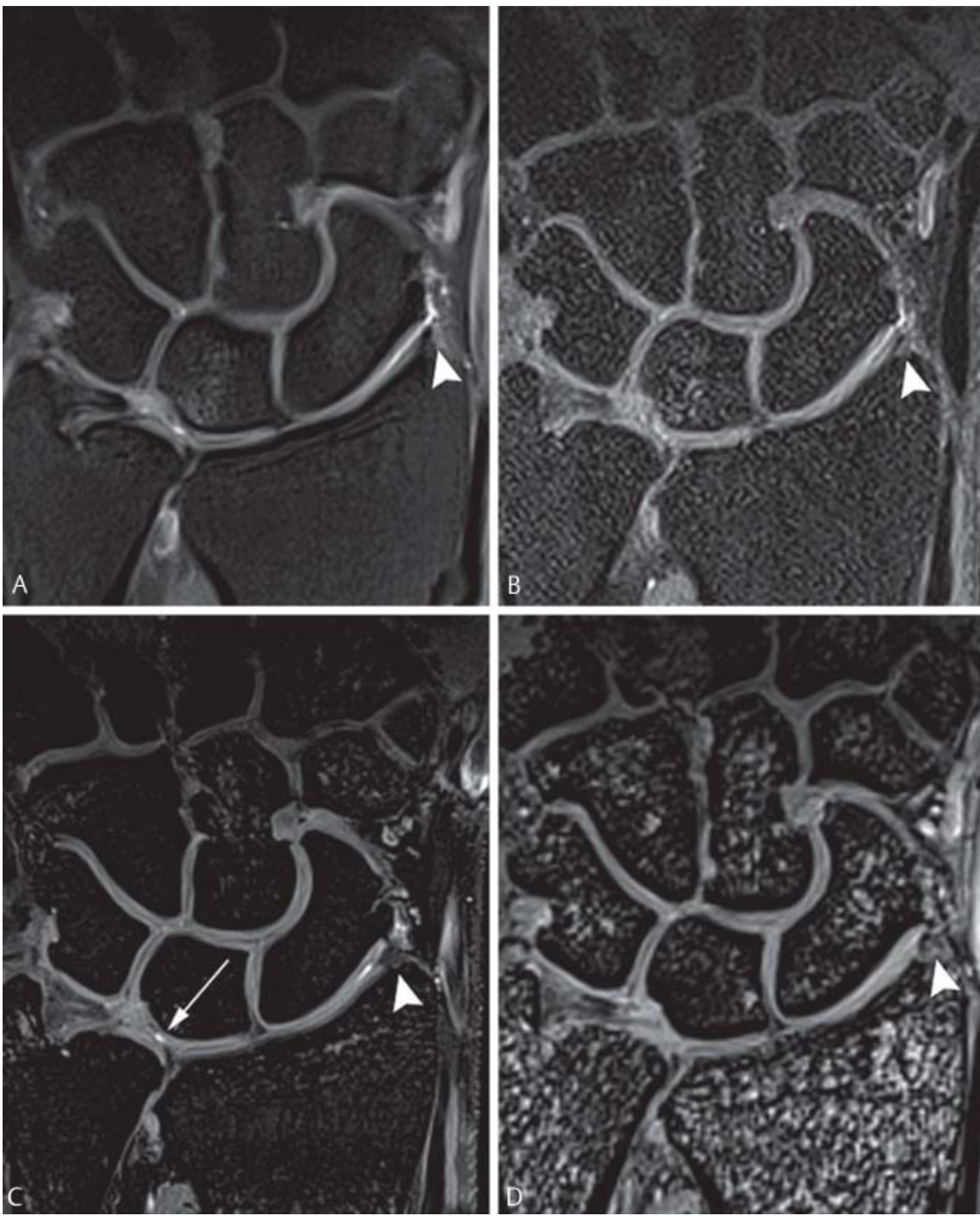

Fig. 3 A-D. Image quality comparison in a 44year-old male patient presenting with ulna impaction syndrome. $3 \mathrm{D}$ TrueFISP still demonstrates the best cartilage image quality and a small focal cartilage defect (arrow in $\mathbf{C}$ ) in the lunate is best depicted in this sequence. Focal banding artifacts at the lateral side of the radius (arrowheads in $\mathbf{C}$ and $\mathbf{D}$ ) are visible in $3 \mathrm{D}$ TrueFISP and $3 \mathrm{D}$ MEDIC and reduce the interpretability of the cartilage in this particular region while other areas are not affected. These artifacts are not present in 2 D PDfs $\mathbf{A}$ and 3 D PDfs SPACE $\mathbf{B}$.

Abb. 3 A-D. Vergleich der Bildqualität bei einem 44-jährigen männlichen Patienten mit Ulnar-Impaction-Syndrom. Die 3D-TrueFISP zeigt weiterhin die beste Bildqualität bezüglich des Knorpels und ein kleiner fokaler Knorpeldefekt (Pfeil in C) ist am besten in dieser Sequenz visualisiert. Fokale „banding" Artefakte an der lateralen Seite der Radius (Pfeilspitzen in C und D) sind in der 3D-TrueFISP und der 3D-MEDIC sichtbar und reduzieren die Beurteilbarkeit in dieser Region, während andere Bereiche nicht betroffen sind. Diese Artefakte sind in der 2DPDfs $\mathbf{A}$ und der 3D-PDfs-SPACE B nicht erkenntlich. disease progression at the knee, particularly due to the high SNR/ CNR values $[16,17]$. A regional decrease in image quality because of artifacts, as present in our patient group, was also reported in other studies $[11,14,18]$. Therefore, especially in the postoperative situation when susceptibility is expected, the use of TSE- instead of GRE-based sequences may be beneficial.

$3 \mathrm{D}$ MEDIC turned out to be the best $3 \mathrm{D}$ sequence for ligaments and the TFCC by winning most of the two-pair comparisons. Also, it turned out to be a good compromise for all structures with high overall image quality, high cartilage scores, the highest SNR within the $3 \mathrm{D}$ sequences and fewer artifacts compared to TrueFISP. T2*-weighted gradient-echo MEDIC combines up to 6 echoes to form an image with a high receiver bandwidth resulting in an increased SNR und reduced susceptibility [19] together with a short acquisition time $[8,19,20]$. In general, MEDIC has only been rarely used for joint imaging, particularly for wrist imaging. Lenk et al. [8] reported a score of 2 (structure is completely detectable/assessable) in all 10 volunteers regarding the visualization of carpal ligaments and TFCC, combined with a high SNR. Pahwa et al. [20] reported 3 D MEDIC at 1.5 T to have a higher sensitivity for the detection of ligament and TFCC tears compared to a T2/PDfs sequence. Chang et al. [21] used a MEDIC sequence at $7 \mathrm{~T}$ and reported excellent visualization of several anatomic structures at the wrist including ligaments, nerves, and vessels. Superficial low intensity artifacts described by Fujinaga [22] at the femoral condyle were also present in our study, but they only moderately lowered the image quality.

In our study, we demonstrated that high-resolution 2 D PDfs provided constantly high image quality scores regarding all assessed items combined with high SNR/CNR values. The low degree of artifacts and the lowest reduction in image quality in the patient group compared to the volunteers further underline the robustness of the sequence. Hence, we recommend including or keeping 2D PDfs in routine imaging protocols of the wrist, as has also been recommended elsewhere [1]. We support the findings of Jung et al. [7], who reported a $2 \mathrm{D}$ TSE sequence to be superior $(p<0.01)$ in the visualization of the scapholunate ligament and wrist cartilage $(\mathrm{p}=0.04)$ when compared to a $3 \mathrm{D}$ gradientecho sequence. Yamabe [2] reported a 2D FSE sequence to have superior anatomic delineation of the SL ligament $(p=0.013)$ when compared to a $3 \mathrm{D}$ FSE sequence in 11 healthy volunteers at 3 T MRI of the wrist. In our study, the $3 \mathrm{D}$ PDfs SPACE sequence was inferior to all other sequences except for the degree of artifacts in patients when compared to $3 \mathrm{D}$ TrueFISP. Most likely this is due to the nature of TSE-based sequences, which are less prone to artifacts when compared to GRE sequences [23]. In the light of the disadvantages, we do not recommend 3D PDfs SPACE in its current form for wrist imaging. Van Dyck et al. [24] also observed 
Table 2 SNR/CNR and image quality comparisons of the $2 \mathrm{D}$ and $3 \mathrm{D}$ sequences. The winners and $\mathrm{p}$-values of each two-pair comparison are displayed.

Tab. 2 Vergleich der SNR/CNR und der Bildqualität der 2D- und 3D-Sequenzen. Gezeigt sind jeweils die Gewinner sowie die p-Werte der Paarvergleiche.

\begin{tabular}{|c|c|c|c|c|c|c|c|c|c|c|c|c|c|c|c|}
\hline \multirow[t]{2}{*}{ volunteers } & \multicolumn{6}{|l|}{ SNR } & \multicolumn{4}{|l|}{ CNR } & \multicolumn{5}{|c|}{ image quality } \\
\hline & cartilage & bone & muscle & fluid & tendon & TFCC & $\begin{array}{l}\text { cartilage- } \\
\text { bone }\end{array}$ & $\begin{array}{l}\text { muscle- } \\
\text { bone }\end{array}$ & $\begin{array}{l}\text { fluid-carti- } \\
\text { lage }\end{array}$ & $\begin{array}{l}\text { muscle- } \\
\text { tendon }\end{array}$ & overall & cartilage & TFCC & ligaments & artifacts \\
\hline $\begin{array}{l}2 \text { D vs. } \\
\text { SPACE }\end{array}$ & $\begin{array}{l}2 \mathrm{D} \\
(p<0.01)\end{array}$ & $\begin{array}{l}2 \mathrm{D} \\
(p<0.01)\end{array}$ & $\begin{array}{l}2 \mathrm{D} \\
(p<0.01)\end{array}$ & $\begin{array}{l}2 \mathrm{D} \\
\mathrm{p}<0.01)\end{array}$ & $\begin{array}{l}2 \mathrm{D} \\
(\mathrm{p}<0.01)\end{array}$ & $\begin{array}{l}\text { n.s. } \\
(p=0.40)\end{array}$ & $\begin{array}{l}2 \mathrm{D} \\
(p<0.01)\end{array}$ & $\begin{array}{l}2 \mathrm{D} \\
(p<0.01)\end{array}$ & $\begin{array}{l}2 \mathrm{D} \\
(p<0.01)\end{array}$ & $\begin{array}{l}2 \mathrm{D} \\
(p<0.01)\end{array}$ & $\begin{array}{l}2 \mathrm{D} \\
(p<0.01)\end{array}$ & $\begin{array}{l}2 \mathrm{D} \\
(p<0.01)\end{array}$ & $\begin{array}{l}2 \mathrm{D} \\
(\mathrm{p}<0.01)\end{array}$ & $\begin{array}{l}2 \mathrm{D} \\
\mathrm{p}<0.01)\end{array}$ & $\begin{array}{l}\text { n.s. } \\
(p=1.0)\end{array}$ \\
\hline $\begin{array}{l}2 \text { D vs. } \\
\text { TruefISP }\end{array}$ & $\begin{array}{l}2 \mathrm{D} \\
(p<0.01)\end{array}$ & $\begin{array}{l}2 \mathrm{D} \\
(p<0.01)\end{array}$ & $\begin{array}{l}2 \mathrm{D} \\
(p<0.01)\end{array}$ & $\begin{array}{l}2 \mathrm{D} \\
(p<0.01)\end{array}$ & $\begin{array}{l}2 \mathrm{D} \\
(p<0.05)\end{array}$ & $\begin{array}{l}\text { TrueFISP } \\
(p<0.01)\end{array}$ & $\begin{array}{l}2 \mathrm{D} \\
(p<0.01)\end{array}$ & $\begin{array}{l}\text { n.s. } \\
(p=0.08)\end{array}$ & $\begin{array}{l}2 \mathrm{D} \\
(p<0.01)\end{array}$ & $\begin{array}{l}2 \mathrm{D} \\
(p<0.01)\end{array}$ & $\begin{array}{l}\text { n.s. } \\
(p=1.0)\end{array}$ & $\begin{array}{l}\text { TrueFISP } \\
(p<0.05)\end{array}$ & $\begin{array}{l}2 \mathrm{D} \\
(p<0.01)\end{array}$ & $\begin{array}{l}2 \mathrm{D} \\
(p<0.05)\end{array}$ & $\begin{array}{l}\text { n.s. } \\
(p=0.16)\end{array}$ \\
\hline $\begin{array}{l}2 \text { D vs. } \\
\text { MEDIC }\end{array}$ & $\begin{array}{l}\text { n.s. } \\
(p=0.51)\end{array}$ & $\begin{array}{l}\text { n.s. } \\
(p=0.72)\end{array}$ & $\begin{array}{l}\text { n.s. } \\
(p=0.66)\end{array}$ & $\begin{array}{l}2 D \\
(p<0.01)\end{array}$ & $\begin{array}{l}\text { n.s. } \\
(p=0.63)\end{array}$ & $\begin{array}{l}\text { MEDIC } \\
(p<0.01)\end{array}$ & $\begin{array}{l}\text { n.s. } \\
(p=0.29)\end{array}$ & $\begin{array}{l}\text { n.s. } \\
(p=0.81)\end{array}$ & $\begin{array}{l}2 \mathrm{D} \\
(p<0.01)\end{array}$ & $\begin{array}{l}\text { n.s. } \\
(p=0.71)\end{array}$ & $\begin{array}{l}\text { n.s. } \\
(p=1.0)\end{array}$ & $\begin{array}{l}\text { n.s. } \\
(p=0.15)\end{array}$ & $\begin{array}{l}\text { n.s. } \\
(p=0.81)\end{array}$ & $\begin{array}{l}\text { n.s. } \\
(p=0.51)\end{array}$ & $\begin{array}{l}\text { n.s. } \\
(p=1.0)\end{array}$ \\
\hline $\begin{array}{l}\text { SPACE vs. } \\
\text { TrueFISP }\end{array}$ & $\begin{array}{l}\text { TrueFISP } \\
(p<0.05)\end{array}$ & $\begin{array}{l}\text { SPACE } \\
(p<0.05)\end{array}$ & $\begin{array}{l}\text { TrueFISP } \\
(p<0.05)\end{array}$ & $\begin{array}{l}\text { TrueFISP } \\
(p<0.01)\end{array}$ & $\begin{array}{l}\text { TrueFISP } \\
(p<0.01)\end{array}$ & $\begin{array}{l}\text { TrueFISP } \\
(p<0.01)\end{array}$ & $\begin{array}{l}\text { TrueFISP } \\
(p<0.01)\end{array}$ & $\begin{array}{l}\text { TrueFISP } \\
(p<0.01)\end{array}$ & $\begin{array}{l}\text { TrueFISP } \\
(p<0.01)\end{array}$ & $\begin{array}{l}\text { n.s. } \\
(p=0.20)\end{array}$ & $\begin{array}{l}\text { TrueFISP } \\
(p<0.01)\end{array}$ & $\begin{array}{l}\text { TrueFISP } \\
(p<0.01)\end{array}$ & $\begin{array}{l}\text { n.s. } \\
(p=0.81)\end{array}$ & $\begin{array}{l}\text { TrueFISP } \\
(p<0.05)\end{array}$ & $\begin{array}{l}\text { n.s. } \\
(p=0.16)\end{array}$ \\
\hline $\begin{array}{l}\text { SPACE vs. } \\
\text { MEDIC }\end{array}$ & $\begin{array}{l}\text { MEDIC } \\
(p<0.01)\end{array}$ & $\begin{array}{l}\text { MEDIC } \\
(p<0.01)\end{array}$ & $\begin{array}{l}\text { MEDIC } \\
(p<0.01)\end{array}$ & $\begin{array}{l}\text { MEDIC } \\
(p<0.01)\end{array}$ & $\begin{array}{l}\text { MEDIC } \\
(p<0.01)\end{array}$ & $\begin{array}{l}\text { MEDIC } \\
(p<0.01)\end{array}$ & $\begin{array}{l}\text { MEDIC } \\
(p<0.01)\end{array}$ & $\begin{array}{l}\text { MEDIC } \\
(p<0.01)\end{array}$ & $\begin{array}{l}\text { MEDIC } \\
(p<0.01)\end{array}$ & $\begin{array}{l}\text { MEDIC } \\
(p<0.01)\end{array}$ & $\begin{array}{l}\text { MEDIC } \\
(p<0.01)\end{array}$ & $\begin{array}{l}\text { MEDIC } \\
(p<0.01)\end{array}$ & $\begin{array}{l}\text { MEDIC } \\
(p<0.01)\end{array}$ & $\begin{array}{l}\text { MEDIC } \\
(p<0.01)\end{array}$ & $\begin{array}{l}\text { n.s. } \\
(p=1.0)\end{array}$ \\
\hline $\begin{array}{l}\text { TrueFISP vs. } \\
\text { MEDIC }\end{array}$ & $\begin{array}{l}\text { MEDIC } \\
(p<0.01)\end{array}$ & $\begin{array}{l}\text { MEDIC } \\
(p<0.01)\end{array}$ & $\begin{array}{l}\text { MEDIC } \\
(p<0.01)\end{array}$ & $\begin{array}{l}\text { TrueFISP } \\
(p<0.05)\end{array}$ & $\begin{array}{l}\text { MEDIC } \\
(p<0.01)\end{array}$ & $\begin{array}{l}\text { n.s. } \\
(p=0.21)\end{array}$ & $\begin{array}{l}\text { MEDIC } \\
(p<0.01)\end{array}$ & $\begin{array}{l}\text { n.s. } \\
(p=0.19)\end{array}$ & $\begin{array}{l}\text { TrueFISP } \\
(p<0.01)\end{array}$ & $\begin{array}{l}\text { MEDIC } \\
(p<0.01)\end{array}$ & $\begin{array}{l}\text { n.s. } \\
(p=1.0)\end{array}$ & $\begin{array}{l}\text { n.s. } \\
(p=0.15)\end{array}$ & $\begin{array}{l}\text { MEDIC } \\
(p<0.01)\end{array}$ & $\begin{array}{l}\text { MEDIC } \\
(p<0.05)\end{array}$ & $\begin{array}{l}\text { MEDIC } \\
(p<0.05)\end{array}$ \\
\hline \multirow[t]{2}{*}{ patients } & SNR & & & & & & CNR & & & & \multicolumn{5}{|c|}{ image Quality } \\
\hline & cartilage & bone & muscle & fluid & tendon & TFCC & $\begin{array}{l}\text { cartilage- } \\
\text { bone }\end{array}$ & $\begin{array}{l}\text { muscle- } \\
\text { bone }\end{array}$ & $\begin{array}{l}\text { fluid-carti- } \\
\text { lage }\end{array}$ & $\begin{array}{l}\text { muscle- } \\
\text { tendon }\end{array}$ & overall & cartilage & TFCC & ligaments & artifacts \\
\hline $\begin{array}{l}2 \text { D vs. } \\
\text { SPACE }\end{array}$ & $\begin{array}{l}2 \mathrm{D} \\
(p<0.01)\end{array}$ & $\begin{array}{l}2 \mathrm{D} \\
(p<0.01)\end{array}$ & $\begin{array}{l}2 \mathrm{D} \\
(p<0.01)\end{array}$ & $\begin{array}{l}2 \mathrm{D} \\
\mathrm{P}<0.01)\end{array}$ & $\begin{array}{l}2 \mathrm{D} \\
(p<0.01)\end{array}$ & $\begin{array}{l}\text { n.s. } \\
(p=0.26)\end{array}$ & $\begin{array}{l}2 \mathrm{D} \\
(p<0.01)\end{array}$ & $\begin{array}{l}2 \mathrm{D} \\
(p<0.05)\end{array}$ & $\begin{array}{l}2 \mathrm{D} \\
(p<0.01)\end{array}$ & $\begin{array}{l}2 \mathrm{D} \\
(p<0.01)\end{array}$ & $\begin{array}{l}2 \mathrm{D} \\
(p<0.01)\end{array}$ & $\begin{array}{l}2 \mathrm{D} \\
(p<0.01)\end{array}$ & $\begin{array}{l}2 \mathrm{D} \\
(p<0.01)\end{array}$ & $\begin{array}{l}2 \mathrm{D} \\
\mathrm{p}<0.01)\end{array}$ & $\begin{array}{l}\text { n.s. } \\
(p=0.87)\end{array}$ \\
\hline $\begin{array}{l}2 \text { D vs. } \\
\text { TruefISP }\end{array}$ & $\begin{array}{l}2 \mathrm{D} \\
(p<0.01)\end{array}$ & $\begin{array}{l}2 \mathrm{D} \\
(p<0.01)\end{array}$ & $\begin{array}{l}2 \mathrm{D} \\
(\mathrm{p}<0.01)\end{array}$ & $\begin{array}{l}2 \mathrm{D} \\
(p<0.01)\end{array}$ & $\begin{array}{l}2 D \\
(p<0.01)\end{array}$ & $\begin{array}{l}\text { TrueFISP } \\
(p<0.01)\end{array}$ & $\begin{array}{l}2 \mathrm{D} \\
(\mathrm{p}<0.05)\end{array}$ & $\begin{array}{l}\text { n.s. } \\
(p=0.58)\end{array}$ & $\begin{array}{l}2 D \\
(p<0.01)\end{array}$ & $\begin{array}{l}2 \mathrm{D} \\
(p<0.05)\end{array}$ & $\begin{array}{l}\text { n.s. } \\
(p=1.0)\end{array}$ & $\begin{array}{l}\text { n.s. } \\
(p=1.0)\end{array}$ & $\begin{array}{l}2 \mathrm{D} \\
(p<0.01)\end{array}$ & $\begin{array}{l}2 \mathrm{D} \\
(p<0.01)\end{array}$ & $\begin{array}{l}2 \mathrm{D} \\
(p<0.01)\end{array}$ \\
\hline $\begin{array}{l}\text { 2 D vs. } \\
\text { MEDIC }\end{array}$ & $\begin{array}{l}\text { MEDIC } \\
(p<0.05)\end{array}$ & $\begin{array}{l}\text { n.s. } \\
(p=0.46)\end{array}$ & $\begin{array}{l}\text { n.s. } \\
(p=0.11)\end{array}$ & $\begin{array}{l}2 \mathrm{D} \\
(p<0.01)\end{array}$ & $\begin{array}{l}\text { MEDIC } \\
(p<0.05)\end{array}$ & $\begin{array}{l}\text { MEDIC } \\
(p<0.01)\end{array}$ & $\begin{array}{l}\text { MEDIC } \\
(p<0.05)\end{array}$ & $\begin{array}{l}\text { n.s. } \\
(p=0.59)\end{array}$ & $\begin{array}{l}2 \mathrm{D} \\
(p<0.01)\end{array}$ & $\begin{array}{l}\text { n.s. } \\
(p=0.32)\end{array}$ & $\begin{array}{l}\text { n.s. } \\
(p=1.0)\end{array}$ & $\begin{array}{l}\text { n.s. } \\
(p=1.0)\end{array}$ & $\begin{array}{l}\text { n.s. } \\
(p=0.19)\end{array}$ & $\begin{array}{l}\text { n.s. } \\
(p=0.56)\end{array}$ & $\begin{array}{l}\text { n.s. } \\
(p=0.87)\end{array}$ \\
\hline $\begin{array}{l}\text { SPACE vs. } \\
\text { TrueFISP }\end{array}$ & $\begin{array}{l}\text { TrueFISP } \\
(p<0.01)\end{array}$ & $\begin{array}{l}\text { SPACE } \\
(p<0.01)\end{array}$ & $\begin{array}{l}\text { n.s. } \\
(p=0.18)\end{array}$ & $\begin{array}{l}\text { TruefISP } \\
(p<0.01)\end{array}$ & $\begin{array}{l}\text { TruefISP } \\
(p<0.01)\end{array}$ & $\begin{array}{l}\text { TrueFISP } \\
(p<0.01)\end{array}$ & $\begin{array}{l}\text { TruefISP } \\
(p<0.01)\end{array}$ & $\begin{array}{l}\text { TruefISP } \\
(p<0.05)\end{array}$ & $\begin{array}{l}\text { TruefISP } \\
(p<0.01)\end{array}$ & $\begin{array}{l}\text { n.s. } \\
(p=0.30)\end{array}$ & $\begin{array}{l}\text { n.s. } \\
(p=0.09)\end{array}$ & $\begin{array}{l}\text { TrueFISP } \\
(p<0.05)\end{array}$ & $\begin{array}{l}\text { n.s. } \\
(p=0.19)\end{array}$ & $\begin{array}{l}\text { n.s. } \\
(p=0.56)\end{array}$ & $\begin{array}{l}\text { SPACE } \\
(p<0.01)\end{array}$ \\
\hline $\begin{array}{l}\text { SPACE vs. } \\
\text { MEDIC }\end{array}$ & $\begin{array}{l}\text { MEDIC } \\
(p<0.01)\end{array}$ & $\begin{array}{l}\text { MEDIC } \\
(p<0.01)\end{array}$ & $\begin{array}{l}\text { MEDIC } \\
(p<0.01)\end{array}$ & $\begin{array}{l}\text { MEDIC } \\
(p<0.01)\end{array}$ & $\begin{array}{l}\text { MEDIC } \\
(p<0.01)\end{array}$ & $\begin{array}{l}\text { MEDIC } \\
(p<0.01)\end{array}$ & $\begin{array}{l}\text { MEDIC } \\
(p<0.01)\end{array}$ & $\begin{array}{l}\text { MEDIC } \\
(p<0.01)\end{array}$ & $\begin{array}{l}\text { MEDIC } \\
(p<0.01)\end{array}$ & $\begin{array}{l}\text { MEDIC } \\
(p<0.01)\end{array}$ & $\begin{array}{l}\text { MEDIC } \\
(p<0.01)\end{array}$ & $\begin{array}{l}\text { n.s. } \\
(p=0.15)\end{array}$ & $\begin{array}{l}\text { MEDIC } \\
(p<0.01)\end{array}$ & $\begin{array}{l}\text { MEDIC } \\
(p<0.01)\end{array}$ & $\begin{array}{l}\text { n.s. } \\
(p=0.87)\end{array}$ \\
\hline $\begin{array}{l}\text { TrueFISP vs. } \\
\text { MEDIC }\end{array}$ & $\begin{array}{l}\text { MEDIC } \\
(p<0.01)\end{array}$ & $\begin{array}{l}\text { MEDIC } \\
(p<0.01)\end{array}$ & $\begin{array}{l}\text { MEDIC } \\
(p<0.01)\end{array}$ & $\begin{array}{l}\text { n.s. } \\
(p=0.81)\end{array}$ & $\begin{array}{l}\text { MEDIC } \\
(p<0.01)\end{array}$ & $\begin{array}{l}\text { MEDIC } \\
(p<0.01)\end{array}$ & $\begin{array}{l}\text { MEDIC } \\
(p<0.01)\end{array}$ & $\begin{array}{l}\text { n.s. } \\
(p=0.62)\end{array}$ & $\begin{array}{l}\text { TrueFISP } \\
(p<0.01)\end{array}$ & $\begin{array}{l}\text { MEDIC } \\
(p<0.01)\end{array}$ & $\begin{array}{l}\text { n.s. } \\
(p=1.0)\end{array}$ & $\begin{array}{l}\text { n.s. } \\
(p=1.0)\end{array}$ & $\begin{array}{l}\text { MEDIC } \\
(p<0.01)\end{array}$ & $\begin{array}{l}\text { n.s. } \\
(p=0.10)\end{array}$ & $\begin{array}{l}\text { MEDIC } \\
(p<0.05)\end{array}$ \\
\hline
\end{tabular}

SNR = signal-to-noise ratio, $C N R=$ contrast-to-noise ratio, $2 \mathrm{D}=2 \mathrm{D}$ PD fs, TFCC = triangular fibrocartilage complex, n.s. = not significant $/$ nicht significant. 


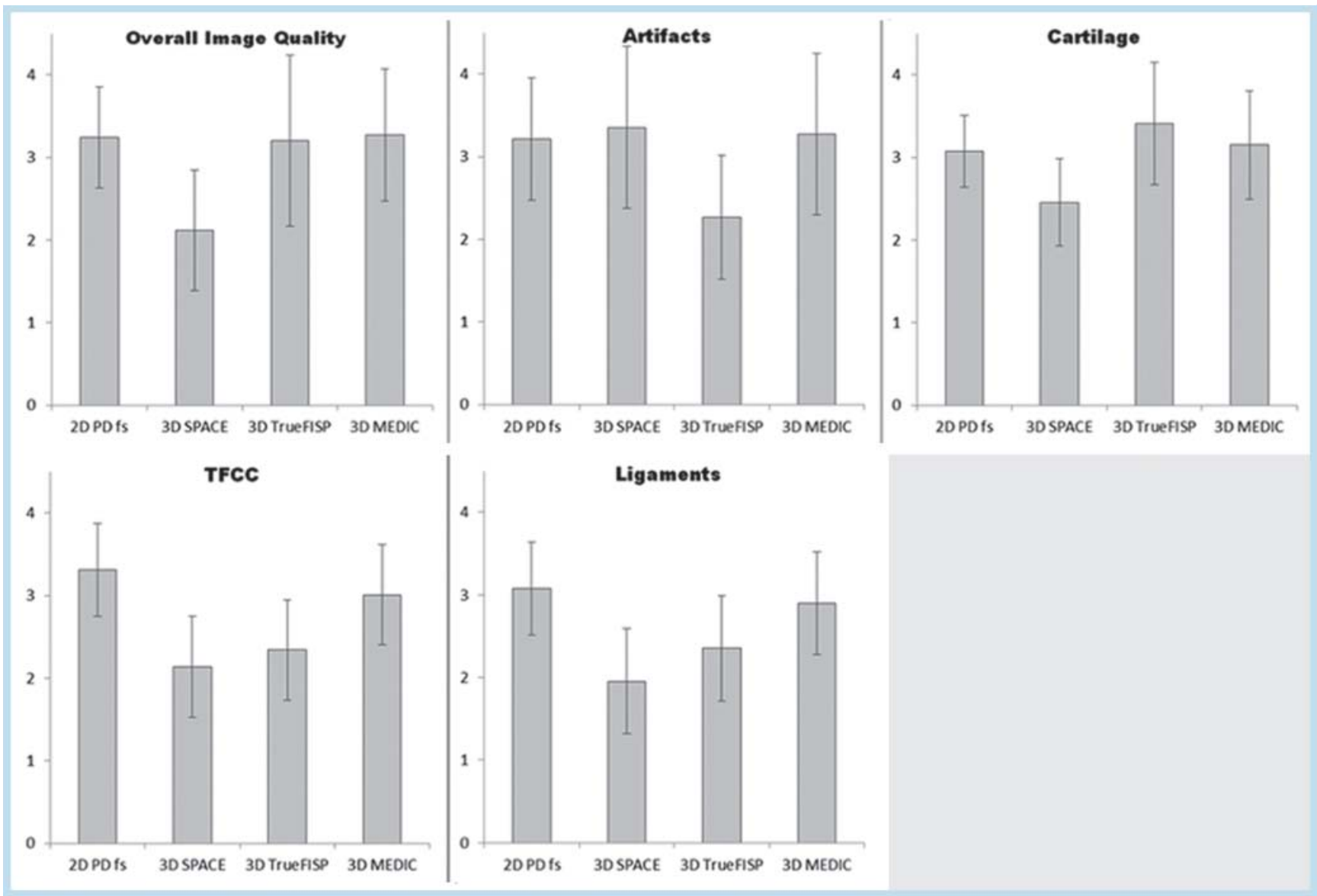

Fig. 4 Image quality ratings of the four tested sequences regarding specific tissues (cartilage, ligaments, TFCC), degree of artifacts (higher ratings correspond to fewer artifacts), and overall image quality in the whole study population. Note: $3 \mathrm{D}$ SPACE $=3 \mathrm{D}$ PDfs SPACE.

Abb.4 Vergleich der Bildqualität der vier untersuchten Sequenzen bezüglich spezifischer anatomischer Strukturen (Knorpel, Ligamente, TFCC), Ausmaß der Artefakte (höhere Bewertungen entsprechen geringeren Artefakten) sowie der Gesamtbildqualität in der gesamten Studienpopulation.

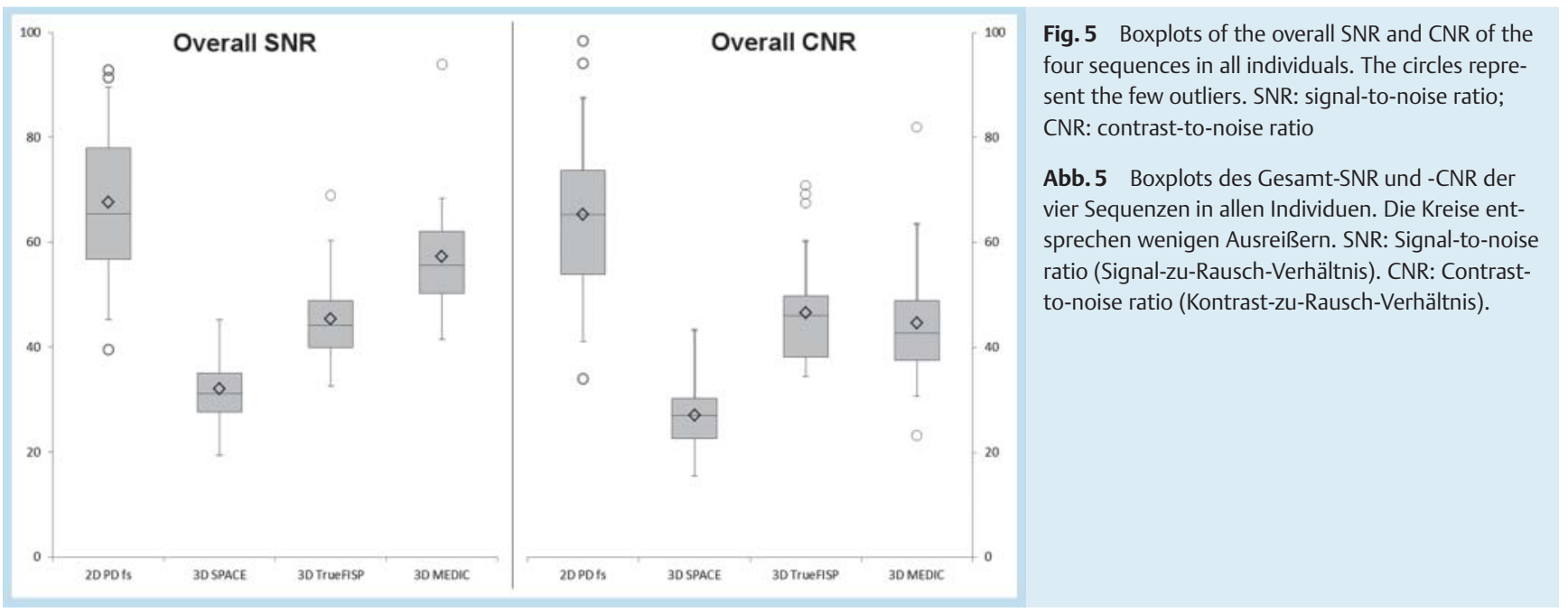

$3 \mathrm{D}$ SPACE to be inferior in the assessment of knee pathologies at $3 \mathrm{~T}$. In this study, $3 \mathrm{D}$ SPACE had a lower specificity for assessing cartilage lesions and lower accuracies for detecting medial meniscus pathologies. Kijowski et al. [25] found a technically similar 3 D FSE CUBE sequence to have a lower specificity compared to a routine protocol in detecting cartilage lesions at the knee, most likely due to decreased in-plane spatial resolution and image blurring due to acquisition of high spatial frequencies late in the echo train. However, there is ongoing progress in the optimization of the SPACE technique with encouraging results $[4,26,27]$. Consequently, there might be a role in the future, for instance in the postoperative setting. 


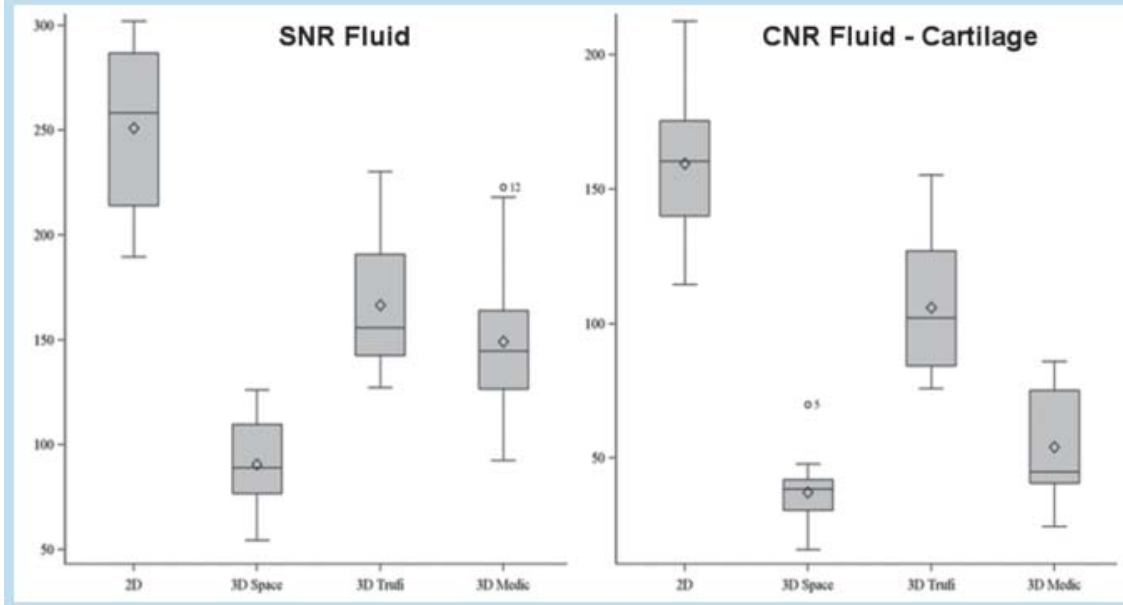

Fig. 6 Selected boxplots to enhance key findings regarding SNR and CNR of specific tissues.

Note that 3D TrueFISP provided the highest CNR of cartilage/fluid and the highest SNR of fluid among the 3D sequences. SNR: Signal-to-noise ratio. CNR: contrast-to-noise ratio.

Abb. 6 Ausgewählte Boxplots zur Illustration von Schlüsselergebnissen hinsichtlich des SNR und CNR in spezifischen anatomischen Strukturen. Beachte, dass die 3D TrueFISP das höchste CNR zwischen Knorpel/Flüssigkeit und das höchste SNR von Flüssigkeit aller 3D-Sequenzen aufweist. SNR: Signal-tonoise ratio (Signal-zu-Rausch-Verhältnis). CNR: Contrast-to-noise ratio (Kontrast-zu-RauschVerhältnis).

\section{Limitations}

First, we have to acknowledge that the study population with 34 included individuals was relatively small. A larger study cohort would allow for higher levels of representativeness and generalizability.

Only in 5 of 18 patients and in none of the healthy volunteers arthroscopy or open surgery was available to correlate pathologic findings. Therefore, lesion detection ability, i. e., sensitivity, specificity, and positive/negative predictive values, could not be systematically evaluated. Specific advantages, for instance the visualization of cartilage damage in 3D TrueFISP, could only be operatively objectified in specific cases. However, healthy individuals and patients with general wrist pain without instability rarely undergo open surgery or arthroscopy and diagnosis is usually based on imaging and clinical examination $[1,2,7,8]$. Also, studies at the wrist with surgical confirmation report on small samples with a bias towards patients with lesions [28].

Although readers were blinded to the sequences, the specific morphologic features of the sequences were apparent when reviewing and may have potentially biased the imaging analysis. Furthermore, the approach to SNR measurements by using the standard deviation of noise in images acquired with parallel imaging is known to be prone to inaccuracies [29]. However, the more exact "difference method" [29] would double the examination time and therefore is hardly feasible in a clinical setting. Due to this circumstance and the fact that also other feasible methods in clinical practice are lacking, the "standard deviation method" remains widely used in comparing MRI sequences while the possible inaccuracy has to be acknowledged $[3,10,11]$. Another limitation we have to acknowledge is the fact that imaging parameters that have influence on the SNR were not equal. Besides differences regarding imaging matrix, TE and TR, the differences in voxel size are of importance. Regarding 3D sequences, TrueFISP was acquired with an in-plane resolution of $0.5 \mathrm{~mm}$ compared to the other $3 \mathrm{D}$ sequences with $0.4 \mathrm{~mm}$. We kept the original resolution as provided by the manufacturer to maintain the potential advantages for wrist imaging (depiction of thin cartilage, TFCC, ligaments) of the thinner 3 D MEDIC and 3D PDfs SPACE. However, the SNR of TrueFISP may therefore be overrated. The primary acquisition with equal in-plane resolutions in 0.4 or $0.5 \mathrm{~mm}$ would reduce the SNR of the 3D TrueFISP or increase the SNR of 3 D PDfs SPACE and 3 D MEDIC, respectively and thus improve comparability regarding this aspect. This is also a problem many studies investigating new sequences or applying sequences on other joints are facing [30-32].

\section{Conclusion}

When imaging the wrist at 3 T, 3 D TrueFISP may be recommended for cartilage imaging. 3D MEDIC was advantageous in the evaluation of ligaments and the TFCC as well as for general wrist imaging. 2D PDfs provided high scores in all assessed items and should be used in standard wrist protocols and should not be replaced by any of the tested $3 \mathrm{D}$ sequences. However, we recommend the additional use of $3 \mathrm{D}$ sequences tailored to the clinical question. The tested $3 \mathrm{D}$ PDfs SPACE sequence is currently not advantageous when compared to the other sequences of our study.

\section{Clinical relevance}

When imaging the wrist at 3 Tesla, the imaging protocol should be tailored to the clinical question and to the patients themselves. 3D imaging sequences provide excellent image quality, i.e. TrueFISP for cartilage imaging and MEDIC for ligaments and the TFCC. In the postoperative situation or when patient movement due to pain is present, 2 D PDfs is more robust compared to the $3 \mathrm{D}$ sequences and maintains a high image quality. Therefore, 2D PDfs accompanied by either 3D TrueFISP or $3 \mathrm{D}$ MEDIC is recommended in modern wrist protocols.

\section{References}

1 Weber MA, Stillfried F, Kloth J et al. Cartilage Imaging of the Wrist Using 3-T MRI. Semin Musculoskelet Radiol 2012; 16: 71 - 87

2 Yamabe E, Anavim A, Sakai T et al. Comparison between high-resolution isotropic three-dimensional and high-resolution conventional two-dimensional FSE MR images of the wrist at 3 tesla: a pilot study. J Magn Reson Imaging 2014; 40: 603-608

3 Ristow $O$, Steinbach L, Sabo G et al. Isotropic 3D fast spin-echo imaging versus standard 2D imaging at $3.0 \mathrm{~T}$ of the knee-image quality and diagnostic performance. Eur Radiol 2009; 19: 1263-1272

4 Notohamiprodjo M, Kuschel B, Horng $A$ et al. 3D-MRI of the ankle with optimized 3D-SPACE. Invest Radiol 2012; 47: 231 - 239 
5 Notohamiprodjo M, Horng A, Pietschmann MF et al. MRI of the knee at 3T: first clinical results with an isotropic PDfs-weighted 3D-TSE-sequence. Invest Radiol 2009; 44: 585 - 597

6 Stevens KJ, Wallace CG, Chen $W$ et al. Imaging of the wrist at 1.5 Tesla using isotropic three-dimensional fast spin echo cube. J Magn Reson Imaging 2011; 33: 908-915

7 Jung JY, Yoon YC, Jung JY et al. Qualitative and quantitative assessment of wrist MRI at 3.0T: comparison between isotropic 3D turbo spin echo and isotropic 3D fast field echo and 2D turbo spin echo. Acta Radiol 2013; 54: 284-291

8 Lenk S, Ludescher B, Martirosan P et al. 3.0 T high-resolution MR imaging of carpal ligaments and TFCC. Fortschr Röntgenstr 2004; 176: 664-667

9 Gold GE, Busse RF, Beehler C et al. Isotropic MRI of the knee with 3D fast spin-echo extended echo-train acquisition (XETA): initial experience. Am J Roentgenol 2007; 188: 1287-1293

10 McMahon CJ, Madhuranthakam AJ, Wu JS et al. High-resolution proton density weighted three-dimensional fast spin echo (3D-FSE) of the knee with IDEAL at 1.5 Tesla: comparison with 3D-FSE and 2D-FSE-initial experience. J Magn Reson Imaging 2012; 35: 361 - 369

11 Friedrich KM, Reiter G, Kaiser B et al. High-resolution cartilage imaging of the knee at 3T: basic evaluation of modern isotropic 3D MR-sequences. Eur J Radiol 2011; 78: 398-405

12 Hayter CL, Gold SL, Potter HG. Magnetic resonance imaging of the wrist: bone and cartilage injury. J Magn Reson Imaging 2013; 37: 1005 - 1019

13 Nagy L. Salvage of post-traumatic arthritis following distal radius fracture. Hand Clin 2005; 21: 489-498

14 Welsch GH, Zak L, Mamisch TC et al. Advanced morphological 3D magnetic resonance observation of cartilage repair tissue (MOCART) scoring using a new isotropic 3D proton-density, turbo spin echo sequence with variable flip angle distribution (PD-SPACE) compared to an isotropic 3D steady-state free precession sequence (True-FISP) and standard 2D sequences. J Magn Reson Imaging 2011; 33: 180-188

15 Welsch GH, Mamisch TC, Weber M et al. High-resolution morphological and biochemical imaging of articular cartilageof the ankle joint at $3.0 \mathrm{~T}$ using a new dedicated phased array coil: in vivo reproducibility study. Skeletal Radiol 2008; 37: 519-526

16 Weckbach S, Mendlik T, Horger W et al. Quantitative assessment of patellar cartilage volume and thickness at 3.0 tesla comparing a 3D-fast low angle shot versus a 3D-true fast imaging with steady-state precession sequence for reproducibility. Invest Radiol 2006; 41: 189-197

17 Duc SR, Pfirrmann CW, Koch PP et al. Internal knee derangement assessed with 3-minute three-dimensional isovoxel true FISP MR sequence: preliminary study. Radiology 2008; 246: 526-535
18 Storey $P, L i W$, Chen $Q$ et al. Flow artifacts in steady-state free precession cine imaging. Magn Reson Med 2004; 51: 115-122

19 Schmid MR, Pfirrmann CW, Koch P et al. Imaging of patellar cartilage with a 2D multiple-echo data image combination sequence. Am J Roentgenol 2005; 184: 1744-1748

20 Pahwa S, Srivastava DN, Sharma $R$ et al. Comparison of conventional MRI and MR arthrography in the evaluation wrist ligament tears: A preliminary experience. Indian J Radiol Imaging 2014; 24: 259-267

21 Chang G, Friedrich KM, Wang L et al. MRI of the wrist at 7 tesla using an eight-channel array coil combined with parallel imaging: preliminary results. J Magn Reson Imaging 2010; 31: 740 - 746

22 Fujinaga Y, Yoshioka H, Sakai T et al. Quantitative measurement of femoral condyle cartilage in the knee by MRI: validation study by multireaders. J Magn Reson Imaging 2014; 39: 972 - 977

23 Singh DR, Chin MS, Peh WC. Artifacts in musculoskeletal MR imaging. Semin Musculoskelet Radiol 2014; 18: 12 - 22

24 Van Dyck P, Gielen JL, Vanhoenacker FM et al. Diagnostic performance of 3D SPACE for comprehensive knee joint assessment at $3 \mathrm{~T}$. Insights Imaging 2012; 3: 603-610

25 Kijowski R, Davis KW, Woods MA et al. Knee joint: comprehensive assessment with 3D isotropic resolution fast spin-echo MR imaging-diagnostic performance compared with that of conventional MR imaging at 3.0 T. Radiology 2009; 252: 486-495

26 Wang J, Wu Y, Yao Z et al. Assessment of pituitary micro-lesions using 3D sampling perfection with application-optimized contrasts using different flip-angle evolutions. Neuroradiology 2014; 56: 1047-1053

27 Dohan A, Gavini JP, Placé V et al. T2-weighted MR imaging of the liver: qualitative and quantitative comparison of SPACE MR imaging with turbo spin-echo MR imaging. Eur J Radiol 2013; 82: e655-e661

28 Hobby JL, Tom BD, Bearcroft PW et al. Magnetic resonance imaging of the wrist: diagnostic performance statistics. Clin Radiol 2001; 56: 50-57

29 Dietrich O, Raya JG, Reeder SB et al. Measurement of signal-to-noise ratios in MR images: influence of multichannel coils, parallel imaging, and reconstruction filters. J Magn Reson Imaging 2007; 26: 375 - 385

30 Notohamiprodjo M, Horng A, Kuschel B et al. 3D-imaging of the knee with an optimized 3D-FSE-sequence and a 15-channel knee-coil. Eur J Radiol 2012; 81: 3441 - 3449

31 Stevens KJ, Busse RF, Han E et al. Ankle: isotropic MR imaging with 3DFSE-cube-initial experience in healthy volunteers. Radiology 2008; 249: $1026-1033$

32 Welsch GH, Juras V, Szomolanyi P et al. Magnetic resonance imaging of the knee at 3 and 7 tesla: a comparison using dedicated multi-channel coils and optimised 2D and 3D protocols. Eur Radiol 2012; 22: 1852 1859 